\title{
THE IMPORTANCE AND DESIGN OF WEB-HOSTING SERVICE AT THE UNIVERSITY OF ZILINA
}

\author{
Martin Hudák ${ }^{1}$, Radovan Madleňák ${ }^{2}$
}

\begin{abstract}
University education by practical experiences is an important factor of the pedagogical process. The genesis of this article was a requirement of web-hosting as a support tool for students. The aim of the article was to define causes and to design university web-hosting. Before web-hosting was designed, a research among the students had been conducted to determine whether they wanted to use this kind of tool. The target group of this research was the segment of students studying at the University of Zilina. The next step was to design the information system for web-hosting and, afterward, to implement it on a dedicated server. After the successful implementation, the last step was to test the functionality of the web-hosting created with several students. All notes, comments, and complaints from the students were taken and would serve as an innovative idea for webhosting in the future.
\end{abstract}

JEL Classification Number: O39, DOI: http://dx.doi.org/10.12955/cbup.v3.588

Keywords: Education, web-hosting, implementation, server

\section{Introduction}

Education is one of the main pillars, in most countries, which is important to be continuously developed and innovated. The same situation is also true in Slovakia (Corejova, Rostasova, \& Hrbanova, 2010). At the University of Zilina, it is possible to study E-commerce and management. During this study, students learn basic principles of management-how to lead people and how to be a good leader (Fabus, Kolarovszka, \& Fabus, 2013). They also learn the foundations of economics and economy. The primary objective of their study is to learn about e-commerce and e-business. Thus, during the course of the study, they must take several subjects related to e-commerce and e-business. For a successful completion of these subjects, they have to create a website or an e-shop, and then upload them onto the Internet (Madlenak, Madlenakova, Svadlenka, \& Salava, 2015). This is only possible through web-hosting. Web-hosting is a type of business that provides server space, web services, and file maintenance for web sites; it is controlled by individuals or companies that do not have their own web servers. The landlord is called a "web-hosting service provider." These services obviously require a certain amount of payment. But, it is also possible to find free web-hosting, which is completely free. The students could use different kinds of free hosting, but they usually come with more disadvantages and limitations. Usually, there is no guarantee of functionality, and technical support is also limited. The unsolicited banner advertisement is inevitably displayed on the website. These disadvantages of free hosting stimulated the design and implementation of developed webhosting at the University of Zilina for students (Madlenak, Madlenakova, \& Kianickova, 2014).

\section{Analysis}

To operate the website, one needs a personal computer with fast Internet connection. However, it is not efficient to operate the server for one website. This is the reason why company started to offer web-hosting services. The provider of web-hosting services must ensure the smooth operation of webhosting (Van Eijk, 2012).

At the present, there are a lot of providers of web-hosting services in Slovakia and also all over the world. The price for that services starts at $5 €$ per month. That web-hosting includes more services, for example, technical support, support of PHP, MySQL database system, and mailbox. To avoid having

\footnotetext{
${ }^{1}$ Ing. Martin Hudák, The Faculty of Operation and Economics of Transport and Communications, University of Zilina, martin.hudak@fpedas.uniza.sk

2 doc. Ing. Radovan Madleňák, PhD, The Faculty of Operation and Economics of Transport and Communications, University of Zilina, radovan.madlenak@fpedas.uniza.sk
} 
to pay for web-hosting services, it is possible to use free-hosting, which is free but comes with a lot of limitations.

The design and implementation of newly developed web-hosting at the university is the third possible solution for students. This opportunity is more difficult in terms of hardware and software. Work experiences with servers and programming skills are also required (Vaculik \& Tengler, 2012). Nevertheless, the university web-hosting has more advantages. Table 1 shows the comparison of all types of web-hosting.

Table 1: The comparison of different types of web-hosting

\begin{tabular}{|c|c|c|c|}
\hline $\begin{array}{c}\text { Services of web- } \\
\text { hosting }\end{array}$ & Type of web-hosting \\
\cline { 2 - 4 } & Commercial web-hosting & Free hosting & $\begin{array}{c}\text { Developed university } \\
\text { web-hosting }\end{array}$ \\
\hline Technical support & YES & NO & YES \\
\hline Banner advertisement & NO & YES \\
\hline Mailbox & YES & YES & YES \\
\hline PHP \& MySQL & YES & YES & Limited \\
\hline Disk space & Mostly unlimited & Limited \\
\hline Payment & YES & NO & \\
\hline Source: Hudak (2014)
\end{tabular}

By comparing the different types of web-hosting, the best solution was found for students. The design and implementation of newly developed university web-hosting is the final result. In the beginning, this process will a lot of effort, but after a successful implementation, it will not be so difficult to manage. The main advantage of this web-hosting is that it is free and there is no unsolicited banner advertisement on the students' websites.

\section{Objectives}

The main objective of this article was to find the right solution of web-hosting for the university. Analysis and comparison of different solutions for web-hosting are also presented in the article. The next step is to choose the right type of web-hosting, and then to implement it. The last phase is to evaluate the current situation concerning the use of web-hosting at the university.

\section{Methods and procedures}

As the mainstream method for design and implementation of the new web-hosting system in university, the sequential design process-the waterfall model-was chosen. This model consists of the following phases: Conception, Initiation, Analysis, Design, Construction, Testing, Production/Implementation, and Maintenance (Madlenak, Madlenakova, Strbova, \& Stefunko, 2014). Requirement specification is listed in the product requirement documentation. The design constituting the software architecture and construction (implementation or coding) led to an actual software. An important phase is integration, testing, and debugging of the actual software to obtain a stabile version of the software. The last phase is installation and software maintenance phase.

At the beginning of the project, a comparison of different types of web-hosting was conducted. After that, a primary research in the form of electronic survey was carried out. The aim of this research was to find out if students wanted to use this type of web-hosting. The second objective of the research was to identify the parameters for university web-hosting. Hardware and software were tested before the implementation of web-hosting in the laboratory. The implementation of web-hosting to the server 
was the next step, followed by testing of web-hosting by students and discussion about functionality of implemented web-hosting. Possible enhancements to the future were also discussed.

\section{Solutions and discussions}

The research was conducted with 90 students who were studying E-commerce and management at The Faculty of Operation and Economics of Transport and Communication. Students answered all of the questions from the survey. The first question was about the interest of students in university webhosting. The evaluation of the first question is illustrated the Figure 1. From Figure 1, it can be seen that students are interested in the university web-hosting.

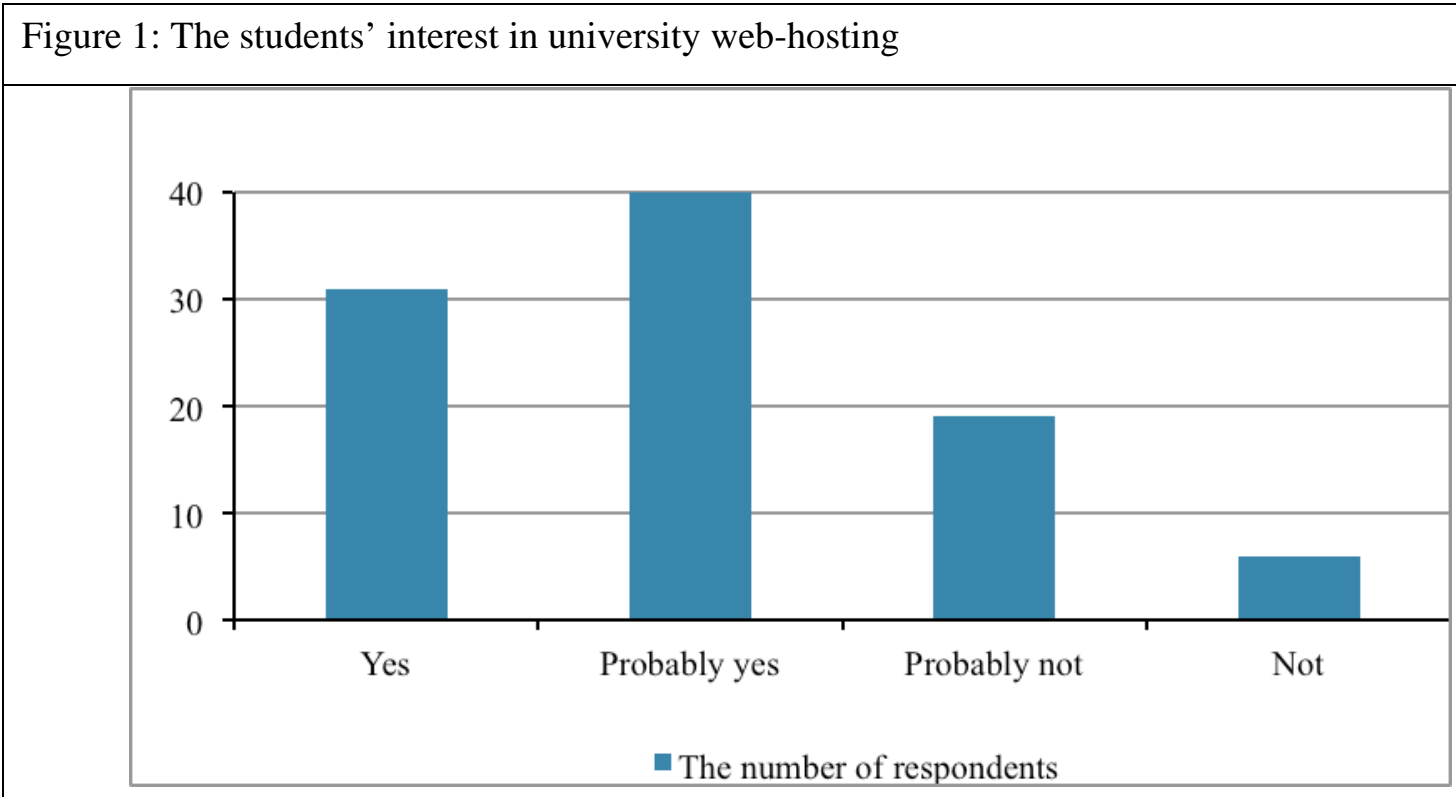

Source: Hudak (2014)

The next objective of the research was to determine the amount of storage that the students needed to have on their accounts. This information is important and comes before the implementation of webhosting. The next question in the survey asked the students whether web-hosting should include such services as PHP script language or MySQL database system. Most of the answers were YES. The last question asked the students to suggest other useful services for web-hosting. The most popular suggestion in this case was the possibility of providing back-up and technical support for web-hosting. On the basis of the primary research, it is evident that the students want to use university web-hosting, and they are aware of its significance.

The first step necessary for a successful implementation of web-hosting was to register the subdomain in the form http://nf106.uniza.sk. IP address of the server on which web-hosting will be implemented is 158.193 .182 .111 .

The first installation was tested on virtual server "VirtualBox.” VirtualBox is a powerful virtualization product for enterprise as well as for home uses. Presently, VirtualBox runs on Windows, Macintosh, Linux, and Solaris hosts and supports a large number of guest operating systems. Within the VirtualBox, the installation of Ubuntu server operating system was tested. The next step was to install Apache web server and MySQL database management system (Droździel, Komsta, \& Krzywonos, 2013). Apache is a public-domain, open source web server developed by a loosely-knit group of programmers. MySQL is the most popular open source SQL database management systemdeveloped, distributed, and supported by Oracle Corporation (Puetz, 2005). The implementation of web-hosting on PC server could start after a successful installation on the virtual server. 
For the successful web-hosting at the university, the use of hardware and software components is needed. The hardware used is a PC server, which is located in a laboratory called "NF106." Its exact name is "HP ProLiant ML370 G6." The hard drive capacity is 4TB, which will be used for webhosting. The operating system for web-hosting used was Ubuntu Server 14.04.2 LTS, which includes a long-term support.

\section{Implementation of web-hosting}

The first step of the implementation was to install Ubuntu server on PC server from a DVD. During this installation, several important settings of system were configured. On the first screen, it was required to choose a language of installation and, then, to configure the keyboard. The next important setting was to configure the network and to type in the system hostname. The hostname is a single word that identifies the system to the network. In this case, the hostname is "nf106" based on the basis of laboratory name. The next step was to setup users and passwords. After that, the installation detected the disk and other hardware. At this stage, it was necessary to partition the disks. After successful partitioning of the disk, there remained several steps to be executed for the installation. One of the last steps was to install GRUB boot loader on a hard drive followed by rebooting the PC. As well as in the testing phase, the next step was to install Apache web server and MySQL database management system. After that, PHP application could be installed. This application was created especially for this university web-hosting. Using this application, it is possible to create and manage web-hosting accounts for students and administrators.

After the complete installation, it was possible to access the homepage of the new web-hosting service. This homepage is http://nf106.uniza.sk. After loading the homepage, the login screen appeared. It was necessary to fill in username and password for a successful login. There are two different types of accounts. The first one is an administor's account. The administrator has the capability to create new students' accounts as well as a new administrator's account. An administrator can create an unlimited number of students' accounts. During the process of creating an account for student, the administrator can fill in a study group of student. Thanks to this functionality, it is possible for the administrator to classify students accounts according to this study group.

The students also have an ability to change their profile data, but it is not possible to change the username. After the first login, it is required to change the password and fill in student's e-mail address. In case the students forget their password, they will be sent a new password for the account via e-mail given. The student's account log in page is shown in Figure 2.

After a successful account authentication, students can start to upload data onto their website. The software used to transfer files in university web-hosting is WinSCP. WinSCP is an open source free SFTP client, and so is FTP client for Windows. Its main function is the secure file transfer between remote and local computer (Vaculik, Michalek, \& Kolarovszki, 2009). When WinSCP is opened, it is necessary to $\log$ in and connect to the server. Hostname for this university web-hosting is nf106.uniza.sk. The second form of hostname is the IP address, which is 158.193.182.111. Username and password of student are also required. After a successful login, students can transfer files onto their new website, which is located on university web-hosting. The link to the website is: http://nf106.uniza.sk/ user.

\section{Testing of web-hosting with students}

After the successful implementation of web-hosting, the next step was to test its functionality with students. The first step of this process, was to have the students log into their accounts, and it was done without any complications. Subsequently, they changed their passwords and filled in e-mail addresses. 
The next step was to log in to WinSCP. This process also went without any complications. WinSCP Login is shown in Figure 3. After a successful log in to WinSCP, students started transferring their data onto the web-hosting service. The last step of this test with the students was to find out whether their websites were functional and visible on the Internet.
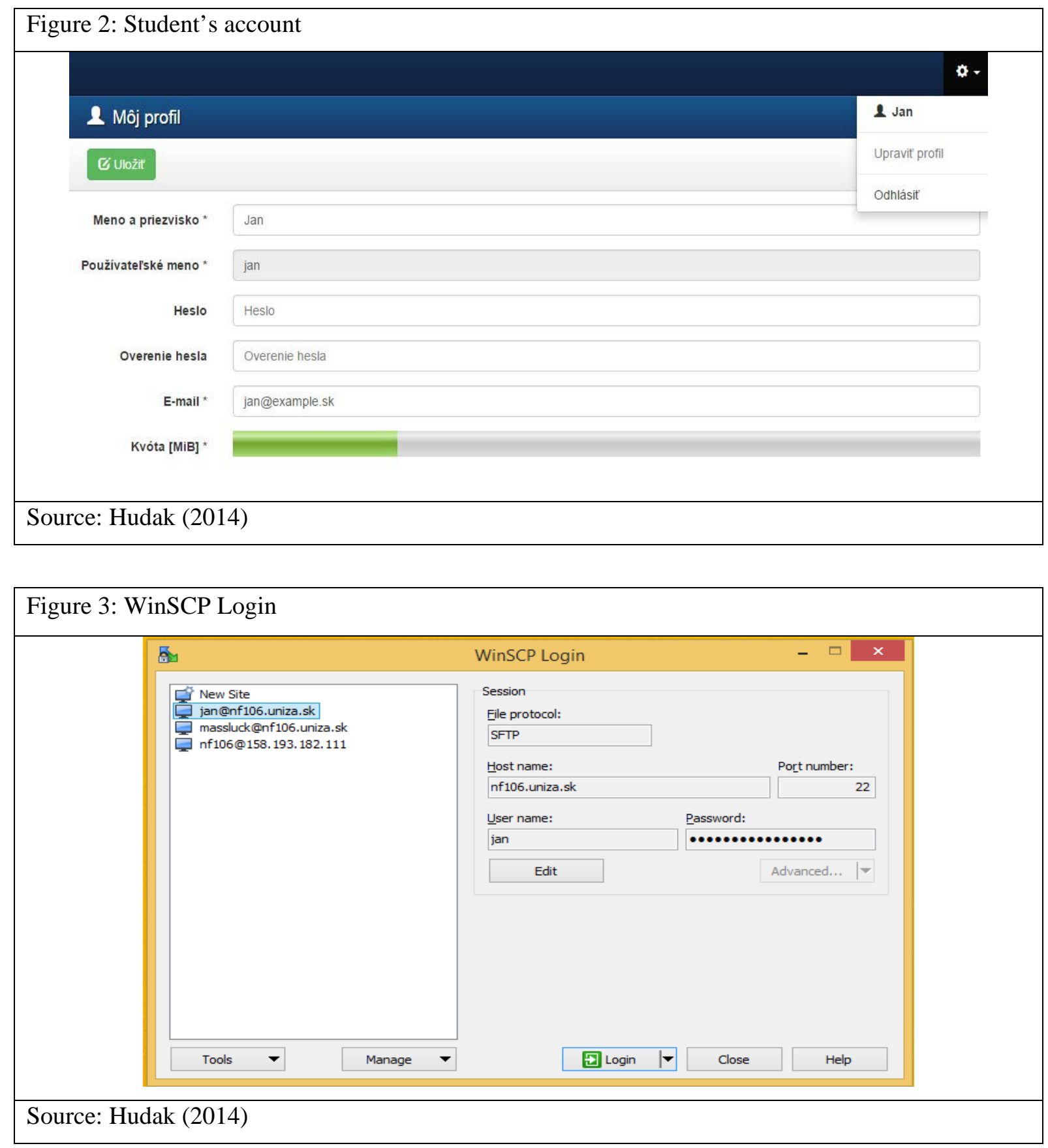

\section{Conclusion}

At the moment, web-hosting service is being utilized by 162 active students. The remaining disk capacity of the web-hosting server is 2,7 TB. Used disk capacity at the present is only 8,3 GB, and, therefore, there is still a lot of free disk space. The plan for the future is to boost the disk capacity of students accounts from $100 \mathrm{MB}$ to $500 \mathrm{MB}$ and also to make university web-hosting available for future students. 
After six months of using the university web-hosting, it is possible to state that web-hosting is an efficient and supportive tool for the student's education. The future aim is to further develop this service and motivate students to accomplish more at the university.

\section{Acknowledgements}

VEGA 1/0721/15 Research on the impact of postal services and telecommunication convergence on regulatory approaches in the postal sector.

\section{References}

Corejova, T., Rostasova, M., \& Hrbanova, K. (2010). Quality of education and ICT support. In: Joint International IGIPSEFI Annual Conference 2010, Trnava, Slovakia

Droździel, P., Komsta, H., \& Krzywonos, L. (2013). Repair costs and the intensity of vehicle use. Transport Problems, 8(3), 131-138

Fabus, J., Kolarovszka, Z., \& Fabus, J. (2013). E-Learning Systems Used at Universities. In: 5th International Conference on Education and New Learning Technologies, Pages: 6242-6249, ISBN: 978-84-616-3822-2, ISSN: 2340-1117

Hudák, M. (2014). Design of web design in university environment. Diploma thesis, University of Zilina

Madlenak, R., Madlenakova, L., \& Kianickova, E. (2014) Designing a Social Network to Support E-learning Activities at the Department of Communications, University of Žilina. Procedia - Social and Behavioral Sciences, Volume 176, 20 February 2015, Pages 103-110, doi:10.1016/j.sbspro.2015.01.449

Madlenak, R., Madlenakova, L., Strbova, J., \& Stefunko, J. (2014). Logo creation algorithm. Komunikacie, 16(3), 120-124

Madlenak, R., Madlenakova, L., Svadlenka, L. \& Salava. D (2015). Analysis of Website Traffic Dependence on Use of Selected Internet Marketing Tools. Procedia Economics and Finance. Volume: 23 Pages: 123-128, DOI: 10.1016/S22125671(15)00355-X, ISSN: 2212-5671

Puetz, C. (2005). The web hosting manager. Highlands Ranch, Colo.: Christoph Puetz.

Vaculik, J., Michalek, I., \& Kolarovszki, P. (2009). Principles of Selection, Implementation and Utilization of RFID in Supply Chain Management, Promet-Traffic \& Transportation, Volume: 21 Issue: 1 Pages: 41-48, ISSN: 0353-5320

Vaculik, J., \& Tengler, J. (2012). Potential of new technologies in logistics services, In: Congress Proceedings - CLC 2012: Carpathian Logistics Congress 2012, Pages 242-250, ISBN: 978-808729436-9

Van Eijk, P. H. J. (2012). Webhosting in the cloud. Cheaper and smarter? In: Computer Measurement Group International Conference, CMG 2012; Las Vegas, NV; United States 